\title{
Cognitive apprenticeship in clinical practice: can it stimulate learning in the opinion of students?
}

\author{
Renée E. Stalmeijer · Diana H. J. M. Dolmans • \\ Ineke H. A. P. Wolfhagen · Albert J. J. A. Scherpbier
}

Received: 12 March 2008/Accepted: 27 August 2008/Published online: 17 September 2008

(C) The Author(s) 2008. This article is published with open access at Springerlink.com

\begin{abstract}
Learning in clinical practice can be characterised as situated learning because students learn by performing tasks and solving problems in an environment that reflects the multiple ways in which their knowledge will be put to use in their future professional practice. Collins et al. introduced cognitive apprenticeship as an instructional model for situated learning comprising six teaching methods to support learning: modelling, coaching, scaffolding, articulation, reflection and exploration. Another factor that is looked upon as conducive to learning in clinical practice is a positive learning climate. We explored students' experiences regarding the learning climate and whether the cognitive apprenticeship model fits students' experiences during clinical training. In focus group interviews, three groups of 6th-year medical students $(N=21)$ discussed vignettes representing the six teaching methods and the learning climate to explore the perceived occurrence of the teaching methods, related problems and possibilities for improvement. The students had experienced all six teaching methods during their clerkships. Modelling, coaching, and articulation were predominant, while scaffolding, reflection, and exploration were mainly experienced during longer clerkships and with one clinical teacher. The main problem was variability in usage of the methods, which was attributed to teachers' lack of time and formal training. The students proposed several ways to improve the application of the teaching methods. The results suggest that the cognitive apprenticeship model is a useful model for teaching strategies in undergraduate clinical training and a valuable basis for evaluation, feedback, self-assessment and faculty development of clinical teachers.
\end{abstract}

Keywords Cognitive apprenticeship - Teaching and learning in clinical practice . Focus group research

R. E. Stalmeijer $(\bowtie)$ · D. H. J. M. Dolmans · I. H. A. P. Wolfhagen

Department of Educational Development and Research, Faculty of Health, Medicine, and Life Sciences, Maastricht University, P.O. Box 616, 6200 MD Maastricht, The Netherlands e-mail: r.stalmeijer@educ.unimaas.nl 


\section{Introduction}

During the clinical years of the medical curriculum students learn and work in an authentic environment where they apply their knowledge to real problems in the context of professional practice (Spencer 2003). The authenticity of the clinical setting and active participation in professional practice are strong motivators for students' learning (Spencer 2003). Learning in a professional environment also helps students to understand the purposes and uses of their (new) knowledge (Collins et al. 1989). This type of learning can be defined as situated learning (Lave and Wenger 1991) because it is characterised by the important role of the (social) setting in which students learn to apply their knowledge. It is claimed that situated learning results in highly meaningful situated cognition and thereby enhances transfer of knowledge to new situations (Brown et al. 1989). Because of the linkage to meaningful practice situations, situated cognition is more powerful than decontextualised knowledge, which, like the theoretical knowledge students acquire during the preclinical phase, is often represented in abstract structures and therefore difficult to translate to concrete situations (Orey and Nelson 1994).

Research indicates that effective learning in medical practice, for instance during clerkships, relies strongly on good clinical supervision (Dolmans et al. 2002; Dornan 2006). The traditional model of learning in practice settings has been that of apprenticeship learning where students start by observing clinical practitioners and are gradually given more tasks to perform as their competence grows. A drawback of this model is that learning is driven by the day-to-day demands of the workplace where learning opportunities and supervision do not have first priority (Collins et al. 1989; Dornan 2006; Taylor and Care 1999). The changing health care environment and developing insights into learning and teaching in clinical practice warrant new models and methods to provide the optimal learning experience for students during their clerkships (Dornan 2006). In general, models for (clinical) teaching should be sufficiently specific to guide clinicians in their role as a clinical teacher (Graffam et al. 2008).

The teaching methods described by Collins and colleagues in the 'cognitive apprenticeship model' (Collins et al. 1989) are highly specific and designed to foster situated learning and thus can be assumed to enhance learning in clinical practice. Within the cognitive apprenticeship model there is a pivotal role for the cognitive processes of experts during complex task performance. Making explicit the generally tacit cognitive processes of experts (Sternberg and Horvath 1999) can elucidate complex task performance and help students in observing, enacting and practising such tasks. Especially in highly cognitive professions, such as medicine, students can benefit from insight into the cognitive processes underlying expert performance; it can make it easier for them to reproduce certain procedures on their own (Taylor and Care 1999). Collins et al. (1989) proposed six teaching methods promoting situated learning by helping students to acquire both cognitive and meta-cognitive skills and focus their observation of expert performance in practice so as to facilitate the development of their own problem-solving skills. Additionally, these methods foster the autonomy of students' learning processes by encouraging students to formulate personal learning goals. In this study we will explore the use of the six teaching methods (modelling, coaching, scaffolding, articulation, reflection, and exploration) of the cognitive apprenticeship model as well as the role of the learning climate. We do so by examining the students' perspective, because based on their first-hand experience of clinical teaching, students as 'consumers' of medical education are uniquely able to provide insights into the effectiveness of these methods in promoting good teaching. 
- Modelling is embodied by teachers when they actively demonstrate and explain skills and procedures to their students.

- Coaching refers to teachers observing students and providing specific and concrete feedback on their performance.

- Scaffolding emphasises that support from teachers for students' learning must be tailored to students' individual knowledge levels. As students become more competent support can be gradually reduced and finally withdrawn (fading).

- Articulation involves teachers questioning students and stimulating them to ask questions.

- Reflection involves ways of stimulating students to deliberately consider their strengths and weaknesses.

- Exploration is aimed at encouraging students to formulate and pursue personal learning goals.

- As for the learning climate, research has pointed to beneficial effects of a positive learning climate, which clinical teachers can foster by showing an interest in students' learning and making students feel respected (Beckman et al. 2003; Kilminster and Jolly 2000; Litzelman et al. 1998).

In summary, we hypothesise that the methods of the cognitive apprenticeship model together with the learning climate constitute a comprehensive theoretical framework for good clinical teaching practices. In the current study we examine whether theory fits practice or, to put it differently, whether students recognise and value the teaching methods of the cognitive apprenticeship model in their experiences of the practices of clinical teaching. In order to examine this, we sought to answer the following research questions:

- Do senior medical students experience these six cognitive apprenticeship methods and the learning climate during clinical training?

- How do senior medical students describe the use of the six cognitive apprenticeship teaching methods and the learning climate in practice during clinical training?

- Which problems do senior medical students perceive concerning the six methods of the cognitive apprenticeship model and the learning climate during clinical training?

- Which steps do senior medical students suggest to improve the use of the six methods of the cognitive apprenticeship model and the learning climate during clinical training?

\section{Method}

\section{Context}

The setting of this study is the 6-year undergraduate curriculum of Maastricht Medical School, the Netherlands. During the first 2 years, students learn basic science knowledge, clinical science knowledge and skills in a problem-based learning environment. Students' first clinical experiences are contacts with real patients in student out-patient clinics which are used as the starting point for their learning in the tutorial groups in Year 3. Years 4 and 5 are devoted to a programme of clerkships in different disciplines in the academic hospital and in affiliated regional hospitals. Rotations differ in duration according to discipline and the sequence of rotations differs between students. Year 6 is divided into two 18-week attachments: one to a hospital ward and one to participation in a research project. During clinical training students are supervised by clinical teachers (specialists and postgraduate 
specialist trainees) using the mini-CEX (Epstein 2007) in frequent observations of students' performance. Students create a portfolio aimed at the development of reflective skills, which they discuss periodically with their mentor.

\section{Participants}

In the academic year 2006-2007, we invited all students $(N=344)$ in Year 6 to participate in our study, assuming that more than 3 years of clinical training create a solid experiential basis for students to engage in in-depth discussion about their clinical training. Via an email all 344 students were invited to participate in focus groups. Selection was based on (near) completion of Year 6 and availability for at least two two-hour sessions. The students were asked to sign up for one of three combinations of two dates and times. A small fee was paid for each hour of participation.

Of the total of 24 respondents, 2 students were eventually unable to participate for personal reasons and 1 student only attended the first session. We composed three groups in accordance with students' preferred date-time options. The female to male ratios of the groups were 4:3 (Group A), 6:2 (Group B), and 5:2 (Group C), which is comparable to the overall 60:40 ratio in the Dutch medical schools. The mean age of the participants was 23 years, which corresponds to the mean age of Dutch medical students in the last year of the undergraduate medical curriculum. The participating students' results on knowledge tests did not differ significantly from those of the other students in the same cohort. All sessions started at 7 p.m. after students had finished in the hospital.

\section{Focus groups}

We used focus groups to explore students' perceptions and ideas about the use of cognitive apprenticeship methods, because we expected them to yield more varied results than individual interviews would (Barbour 2005).

For the six teaching methods described by Collins et al. (1989) and for learning climate we designed vignettes to give the students a clear idea of the themes to be discussed. The vignettes served as the starting point for the group interview and the moderator encouraged the students to tell illustrative anecdotes, discuss problems and offer suggestions for improvement.

With an interval of 1 or 2 weeks the groups met twice for about two hours. At the start of the first session the moderators assured the students that confidentiality was guaranteed. Moderator I (AJJAS) acted as facilitator of the discussions while Moderator II (RES) wrote a summary of what was said and by whom. The sessions were audiotaped and transcribed literally. The students received a summary of each session and were invited to offer corrections and comments. Based on this some minor adjustments were made and in the second session more attention was paid to the way in which the teaching methods were used. Because no new topics with regard to the research questions were emerging at the end of the second session, it was decided that saturation had been reached and no further sessions were scheduled.

Analysis

All group sessions were audiotaped and transcribed literally by two student-assistants. The principal investigator (RES) read all the transcripts and wrote a preliminary, descriptive 
summary of the findings answering the research questions for each teaching method/ vignette and learning climate. Next, two independent researchers (DHJMD and IHAPW) read the transcripts and independently wrote a summary for one teaching method. The two researchers and RES then discussed, compared and modified the summaries until consensus was reached on the final version. Finally, RES completed the summaries for the other teaching methods and the learning climate. For respondent validation (Barbour 2005) all participants were asked to comment on the preliminary findings. Of the 21 participants, 14 responded (67\%), 6 each from groups A and B and 2 from group C. Their comments led to minor modifications and all the respondents stated that the findings accurately reflected the focus group sessions.

\section{Results}

The students said they had encountered all of the six teaching methods during clinical training and cited both positive and negative examples. Differences between students' experiences are mostly related to individual teachers, hospitals, disciplines and students (pro-active or not, amount of experience).

We present the results for each of the six teaching methods and for learning climate separately. Starting with the vignette in question we present descriptive summaries of students' experiences with the method, their descriptions of the method in action, problems with the method and suggestions for improvement. We illustrate these by quotations from the interviews. A letter number combination identifies the quotations by focus group and student.

\section{Modelling}

\footnotetext{
Vignette 1: Modelling

The clinical teacher demonstrated different skills. During or after the demonstration the teacher explained the task identifying aspects that are important for task performance. The teacher created opportunities for me to observe him/her. The teacher gave me ideas about how I wanted or did not want to function when working as a doctor in the future.
}

Students said that looking back on their clinical training they could think of several instances of modelling, especially when new topics or technical skills were introduced. They noted that they could still remember why and how a certain procedure was performed when a teacher had explained it to them very clearly. The main perception of students about role modelling was that they continuously observed clinicians and considered whether they wanted to be like them or not. Students expressed a high regard for teachers who explained and demonstrated things repeatedly and actively involved students in modelling by thinking aloud and by explaining why they performed certain actions.

Yes, well with neurology in Heerlen, I did not particularly like that rotation, but what I did like very much was that the first few days, I think it was the second day when I was shadowing the house officer and she extensively demonstrated the full neurological examination from head to toe. And after that it was like just do it yourself, but that one time, demonstrating it. For of course it is an extensive 
examination, like what was it like in reality, I really like that. It was only once, but it was really good that they did it just to see how to do it systematically. (B8)

Modelling was not a regular occurrence, however, and students were not always actively engaged in the process. Often clinicians did not take enough time to model activities in a sufficiently explicit manner. Teachers frequently left it largely unexplained why certain actions were performed and certain questions asked. As a result students sometimes felt they were just imitating what they had seen a doctor do during physical examination but did not have a clue as to what they were doing or why they were doing it.

That you just do what you have seen them doing, and that is often just a poor example of how it is supposed to be done. And that you, just because they do it that way, that you do it that way too ... But actually that is not how it is supposed to be done. (C5)

Students suggested that modelling would be greatly enhanced when teachers would explain the rationale and method of their actions. Most of the time the students just watched procedures being performed without any active involvement on their part.

\section{Coaching}

Vignette 2: Coaching

The clinical teacher observed me on several occasions during my rotation in his/her department. After observing me the teacher gave me feedback, which gave me a better idea of which aspects I could improve and how.

For the students, coaching was mainly associated with being observed during assessments, especially when presenting a patient history. Although the students indicated that they did not always like being observed, there was general appreciation of observation when it was followed by suggestions as to what and how they could do better. Students with more experience in clinical practice were more confident and found it easier to ask for observation and feedback.

Yes, you really learn from it [being observed], I don't really like it, but you do learn a lot when a person gives you decent feedback afterwards, like hey look, in that part it would have been better if you had done it that way. (B3)

Time constraints played a part and, despite their lack of enthusiasm for being observed, students felt more observation was possible. Students also reported that observation was mostly limited to parts of activities, such as reporting after performing a history and physical examination.

Students said they wanted a stronger emphasis on feedback rather than assessment because the latter offered few concrete directions for improvement. According to the students, the assessment checklists were not helpful in providing specific feedback, because the clinicians were only required to check boxes before giving a final judgement.

The students expected that matters would improve when they were assigned to one personal supervisor who could observe them more frequently. Feedback training for clinical teachers was also expected to be helpful. The students asked for more specific feedback in addition to global ratings. 
Scaffolding

Vignette 3: Scaffolding

The clinical teacher was aware of my previous experience and offered sufficient opportunity for independent activities. The teacher also helped when activities were difficult for me. The teacher gradually reduced support for certain activities so that I could become more independent.

Scaffolding was mainly experienced by the students during longer rotations-for example the 10-week family medicine clerkship-where they had repeated one-on-one contact with one supervisor. Some students said they had experienced it during shorter rotations too but this depended on individual supervisors and hospitals' specific approach to students.

Scaffolding motivated students and they appreciated it when supervisors showed an interest in and took account of their level of skills and knowledge.

I think it mostly occurs during the longer rotations. That at first you are told 'come along and observe in the outpatient clinic, in the operating theatre or an emergency patient or whatever' and after the first two weeks, you were told like 'well, now you have some idea of what to do, come on.' (B6)

The shorter the rotation, the less likely they were to experience scaffolding according to the students. Because they were always shadowing different people, the students felt that none of the supervisors had a good idea of their knowledge and skills. One student argued that it would be unrealistic for them to expect the teachers to really know their level of knowledge and skill because a teacher would have to be virtually omniscient and omnipresent to manage that.

It sort of suggests that teachers are like Father Christmas or God, who knows all along whether you can do something or not and who is not just watching you all of the time, but also helps you when things are difficult and otherwise allows you to manage on your own. And well, I think that is very difficult to achieve. (C4)

Students say they would like to feel that it was safe for them to inform their supervisors of their level of competence so that supervisors can act accordingly. They suggested that things could improve greatly, if teachers would ask them in which year they were and which rotations they had completed. Students also said they liked the concept of 'constructive friction'. In other words they liked to be challenged to make an effort to move to the next level.

It would actually be quite good if in a manner of speaking you were literally asked at the start “just tell me honestly what you know and don't know, it won't be held against you" but that someone just knows the gaps in your knowledge so that you can do something about it. (A5)

\section{Articulation}

\section{Vignette 4: Articulation}

The clinical teacher asked me to explain my actions and helped me become aware of gaps in my knowledge and skills. The teacher questioned me regularly to increase my understanding and encouraged me to ask questions. 
The students said they had experienced aspects of articulation throughout the clinical years. Whenever it occurred it deepened their knowledge and experience and enhanced their memory. Articulation did not depend on the amount of time spent with supervisors and occurred right from the start of clerkships.

(...) That doctor had really made it an art to start with a simple question making you feel like o.k. I know a lot of basic knowledge and then at a certain point start firing challenging questions at you about things you didn't know yet, first brainstorm about that with you and then ask you to take the remaining issues home with you and follow up on them the next day. Yes, well, er that is really an art you would want to cultivate. (C2)

Articulation was not always effective and students noted that occasionally it focused on highly specialised knowledge on a supervisor's pet topic. An experience shared by all students was that supervisors after telling them to 'look it up' rarely followed up on that. This was qualified as frustrating. Students sometimes felt that telling them to 'look it up' was a good way for teachers to be rid of them. Nevertheless, it was also clear that some supervisors were very good at asking probing questions to stimulate students to learn whereas other teachers tended to use articulation primarily to expose gaps in students' knowledge.

Another point made by the students was that they gradually developed a pro-active attitude towards articulation as their confidence and knowledge grew or they felt safer with a supervisor or in a specific learning environment. Nevertheless, it was sometimes difficult for them to ask the 'right' questions because of lack of knowledge in a specific domain.

Also what they ask you to look up. Of course it is easy for a doctor to find lots of gaps in students' knowledge. And then they ask about very specific details, but what is the point for a student to look that up only to find that you will never use it anyway. (A5)

Yes, but sometimes you just don't know what to ask. For then, for instance when you do not recognise things, you just don't [ask about them]. (C5)

It was the students' final conclusion that articulation should be applied more often because it stimulated learning and that teachers who told them to 'go and look it up' should follow up on this and discuss it with them afterwards.

\section{Reflection}

\section{Vignette 5: Reflection}

The clinical teacher encouraged me to become aware of my strengths and weaknesses and to consider what I could do to improve things.

For the students, reflection was mainly associated with the reflective portfolio and their portfolio mentor rather than with their clinical training. During clerkships reflection was generally limited to a few scattered incidents on longer rotations, to one-on-one contacts with supervisors and to contacts with a few supervisors who were interested in reflection. Some of the supervisors who tried to encourage reflection focused exclusively on strengths and weaknesses but failed to give directions for improvement. 
The supervisors who engaged in reflective activities were typically those with whom the students had contact for a longer time or who could be characterised as having a proactive approach to education.

Students recognised the value of (self-)reflection, which in their opinion was stimulated by multi-source feedback, by video-tapes of their performance as a starting point of discussions, and by a favourable climate in the department. According to the students what they appreciated most in reflection was supervisors suggesting ways in which they could address their strengths and weaknesses.

Exploration

Vignette 6: Exploration

The clinical teacher encouraged me to formulate learning objectives and pursue them. The teacher challenged me to keep learning new things.

Exploration was experienced infrequently by students and only during longer rotations and only with some supervisors. Students were told to 'go and look things up' more often than they were asked to formulate personal learning goals. Moreover, the students felt they did not have time for personal learning goals because they were too busy with other assignments. There were supervisors who thought learning objectives should be the same for all students, leaving no room for personal learning goals. Other supervisors said they 'did not believe in learning goals'. On the whole, most students perceived exploration as a component of their portfolio or associated it with a particular form for analysing patient cases.

In the few instances where attention was paid to learning goals, the students experienced it as highly simulating and said it helped them focus their learning process. The students also said that documented personal learning goals could be useful in impelling supervisors to provide more meaningful learning experiences.

Well, in the outpatient clinic it was o.k. when you were sitting there or had actually done things, that was much better of course. But that when you were finished you would talk about the patients who had been seen and why not this and why not that. And that afterwards you would say, hey I don't know this, I'll look it up. Or that she sometimes said like "that is a really good question, but look it up for yourself first and then we will talk about it tomorrow for that way you will learn more than when I just give you the answer right now." (B6)

As a way of promoting exploration, students suggested teachers should pay more attention to and help them formulate individual learning objectives and opportunities to pursue them.

General learning climate

Vignette 7: General Learning Climate

The clinical teacher created a safe learning environment and took enough time to coach me. The teacher was interested in me as a student and treated me with respect.

The general learning climate was recognised as an aspect that was always present either in a positive or in a negative way. Students said the general learning climate largely 
determined to what extent they felt free, for example to ask questions. According to the students, supervisors who created a good learning climate made them feel that they were treated as equals and that the supervisor was genuinely interested in their learning. Feeling respected by their teachers was considered of crucial importance by the students. Additionally, several students said that students could also influence the learning climate by being positive and enthusiastic.

I mean in my experience there were occasions when I felt more like an equal ... That house officers come up to you like 'hey a new student' and shake hands 'I am ...' That makes you feel much better (...) then I immediately feel that it is safe to ask questions ... that is much easier than when everybody just waits until you approach them. (B3)

It is also good ... when there is someone, er someone whose task it is to guide you who says 'when there is a problem, if things aren't going smoothly, just come and see me, it can be quite anonymous (C1); A safety net (C4); Yes, some sort of safety net, That you can be sure in any case that when you have a confrontation with one of your bosses, that in any case there is someone to whom you can go and talk about it. (C1)

Whenever students felt the learning climate was negative, they did not feel free to ask questions and it hindered their learning. Students also described the learning climate as a delicate balance which was easily disturbed. For instance, when you did something wrong in the eyes of a supervisor, a good learning climate could easily turn into an unpleasant one. Frequently, supervisors showed no interest in students at all, which made students systematically avoid those supervisors.

As for respect it has happened that I politely asked the ward doctor in the morning 'can I come with you today?' 'Well, is that really necessary? Oh well all right then.' Well then you are following them the whole day with a look on your face like he does not want me along ... Then you don't feel comfortable and you do not feel that you are treated with respect. (B8)

Supervisors being more respectful to students and showing a genuine interest in their presence and learning activities would go a long way towards optimising the general learning climate.

\section{Discussion and conclusions}

Based on the premise that clinical teaching can be improved when it is supported by a model of clinical teaching that is specific enough to offer practical guidance to clinical teachers, we explored the applicability of the cognitive apprenticeship model to undergraduate clinical training (Brown et al. 1989; Collins et al. 1989). In focus group interviews, we elicited the opinions of senior medical students about the occurrence of the methods during their clerkships, how they valued the methods and how their use might be improved. The views of the students appear to support the applicability of the cognitive apprenticeship model to undergraduate clinical training. The students recognised and narrated experiences with all of the methods, although modelling, coaching and articulation predominated, while scaffolding, reflection and exploration were mostly reported to occur during longer attachments and in contacts with personal mentors. Our additional investigation of the impact of the learning climate on clinical teaching revealed its importance to students, confirming the results of previous studies demonstrating its strong 
impact on the learning process of students (Kilminster and Jolly 2000; Litzelman et al. 1998).

Apart from support for the applicability of the methods of the cognitive apprenticeship model from the point of view of the students, our study revealed insights into problems relating to the methods and ways to resolve them. The main problem reported by the students was the variability in the use of the teaching methods, which they regretted and attributed to clinical teachers not taking enough time for teaching or to lack of teaching skills. This is confirmed by reports from other studies about the negative impact of time constraints and lack of formal teacher training (Cottrell et al. 2002; Spencer 2003). Interestingly, and in line with Dornan's (2006) description of the importance of proactive behaviour of students for learning in a clinical setting, the suggestion was made that students might stimulate the use of certain teaching methods by their own proactive behaviour. Another interesting observation by students is that some teaching methods may require prolonged engagement in one discipline and/or with one individual teacher, which is supported by findings from research into a longitudinal clerkship programme showing that students highly appreciated being attached to one individual teacher and that it helped them to reach a deeper level of engagement (Milhalynuk et al. 2008).

Very practical suggestions for improving clinical teaching made by the students relate to scaffolding, modelling and coaching. In order to remedy a problem that hampers scaffolding, namely teachers being insufficiently informed of students' knowledge and skill levels to gear their teaching to students' needs, the students proposed that teachers should be encouraged to ask them in which year they were and which rotations they had completed. A proposal intended to enhance modelling was for clinicians to pay more attention to explaining to students why and how they performed certain procedures. An important recommendation aimed at improving coaching concerned ways, including teacher training, to promote constructive and individual feedback.

A limitation of this study is that our study population consisted of volunteers. Although they resemble their peers in gender, age and test results, it cannot be ruled out that this was a group of students with a stronger than usual interest in education compared to their peers. Another limitation is that we only explored the perceptions of students and not those of other stakeholders in clinical education such as the clinical teachers. Obviously, exploration of the teachers' opinions regarding the usefulness of the cognitive apprenticeship model would widen the scope of our insight.

As we stated earlier, the cognitive apprenticeship model combined with learning climate covers aspects of clinical teaching that resonate with students' experiences and offer leads to improve teaching. Although further research is needed to establish the usefulness of the model, we believe that it is safe to say that the model shows promise as an instrument for studies focusing on evaluation, feedback, self-assessment and faculty development in clinical teaching.

Acknowledgements The authors would like to thank all students who participated in the focus group research and provided their feedback on the results. They also wish to thank Mereke Gorsira for editing the final version.

Open Access This article is distributed under the terms of the Creative Commons Attribution Noncommercial License which permits any noncommercial use, distribution, and reproduction in any medium, provided the original author(s) and source are credited. 


\section{References}

Barbour, R. S. (2005). Making sense of focus groups. Medical Education, 39, 742-750.

Beckman, T. J., Lee, M. C., Rohren, C. H., \& Pankratz, V. S. (2003). Evaluating an instrument for the peer review of inpatient teaching. Medical Teacher, 25(2), 131-135.

Brown, J. S., Collins, A., \& Duguid, P. (1989). Situated cognition and the culture of learning. Educational Researcher, 18(1), 32-42.

Collins, A., Brown, J. S., \& Newman, S. E. (1989). Cognitive apprenticeship: Teaching the crafts of reading, writing, and mathematics. In L. B. Resnick (Ed.), Knowing, learning, and instruction: Essays in honor of Robert Glaser (pp. 453-494). Hillsdale, New Jersey: Lawrence Erlbaum Associates, Inc.

Cottrell, D., Kilminster, S., Jolly, B., \& Grant, J. (2002). What is effective supervision and how does it happen? A critical incident study. Medical Education, 36, 1042-1049.

Dolmans, D. H. J. M., Wolfhagen, I. H. A. P., Essed, G. G. M., Scherpbier, A. J. J. A., \& van der Vleuten, C. P. M. (2002). The impacts of supervision, patient mix, and numbers of students on the effectiveness of clinical rotations. Academic Medicine, 77(4), 332-335.

Dornan, T. (2006). Experience based learning. Learning clinical medicine in workplaces. Dissertation, Maastricht University, Maastricht.

Epstein, R. M. (2007). Assessment in medical education. New England Journal of Medicine, 356, 387-396.

Graffam, B., Bowers, L., \& Keene, K. N. (2008). Using observations of clinicians' teaching practice to build a model of clinical instruction. Academic Medicine, 83(8), 768-774.

Kilminster, S. M., \& Jolly, B. C. (2000). Effective supervision in clinical practice settings: A literature review. Medical Education, 34, 827-840.

Lave, J., \& Wenger, E. (1991). Situated learning: Legitimate peripheral participation. Cambridge: Cambridge University Press.

Litzelman, D. K., Stratos, G. A., Marriott, D. J., \& Skeff, K. M. (1998). Factorial validation of a widely disseminated educational framework for evaluating clinical teachers. Academic Medicine, 73(6), 688695.

Milhalynuk, T., Bates, J., Page, G., \& Fraser, J. (2008). Student learning experiences in a longitudinal clerkship programme. Medical Education, 42, 729-732.

Orey, M. A., \& Nelson, W. A. (1994). Situated learning and the limits of applying the results of these data to the theories of cognitive apprenticeships. Paper presented at the Proceedings of Selected Research and Development Presentations at the 1994 National Convention of the Association for Educational Communication and Technology Sponsored by the Research and Theory Division, Nashville, TN.

Spencer, J. (2003). Learning and teaching in the clinical environment. ABC of learning and teaching in medicine. British Medical Journal, 326, 591-594.

Sternberg, R. J., \& Horvath, J. A. (Eds.). (1999). Tacit knowledge in professional practice. Researcher and practitioner perspectives. Mahwah, New Jersey: Lawrence Erlbaum Associates Inc.

Taylor, T. K., \& Care, W. D. (1999). Nursing education as cognitive apprenticeship: A framework for clinical education. Nurse Education, 24(4), 31-36. 